\title{
GAMIFICAÇÃO E O DESENVOLVIMENTO DA CONSCIÊNCIA FONOLÓGICA NO CICLO ALFABETIZADOR
}

\section{ARTIGO ORIGINAL}

ALVES, Claudia Andreia ${ }^{1}$, SCHLICKMANN, Maria Sirlene Pereira ${ }^{2}$

ALVES, Claudia Andreia. SCHLICKMANN, Maria Sirlene Pereira. Gamificação e o desenvolvimento da consciência fonológica no ciclo alfabetizador. Revista Científica Multidisciplinar Núcleo do Conhecimento. Ano. 06, Ed. 10, Vol. 01, pp. 4571. Outubro 2021. ISSN: 2448-0959, Link de acesso: https://www.nucleodoconhecimento.com.br/educacao/desenvolvimento-daconsciencia,

DOI: 10.32749/nucleodoconhecimento.com.br/educacao/desenvolvimento-da-consciencia

\section{RESUMO}

Com o advento de tecnologias que exploram novas linguagens através de imagens digitais ou eletronicamente produzidas, promovendo interatividade e utilização de games, abordagens pedagógicas tem, cada vez mais, feito uso destes softwares, aliando ao processo de ensino e aprendizagem a gamificação. Assim, o tema deste artigo é o desenvolvimento da consciência fonológica por meio da gamificação durante o ciclo alfabetizador. O problema que norteou esta pesquisa foi: como a gamificação pode auxiliar as crianças na formação da consciência fonológica, no ciclo alfabetizador? A partir da pergunta-problema, traçou-se como objetivo geral desta pesquisa: compreender como a gamificação pode auxiliar as crianças na formação da consciência fonológica, no ciclo alfabetizador. Para alcançar o objetivo proposto, no que se refere aos procedimentos de coleta de dados, desenvolveu-se uma pesquisa bibliográfica. Quanto ao nível, trata-se de uma pesquisa exploratória com abordagem qualitativa. A análise dos dados constituiu-se de forma dialógica,

\footnotetext{
${ }^{1}$ Licenciada em Pedagogia e Especialista em Inovação da Educação.

2 Professora. Doutora em Ciências da Linguagem pelo PPGCL da Universidade do Sul de Santa Catarina.
}

$\mathrm{RC}: 98312$

Disponível em:

https://www.nucleodoconhecimento.com.br/educacao/desenvolvimento-da- 
considerando obras de autores que versavam sobre gamificação, consciência fonológica e processo inicial de alfabetização. No que concerne aos resultados, pôde-se perceber que o uso de jogos educacionais digitais promove um ambiente agradável e lúdico de aprendizagem e que contribui com o desenvolvimento da consciência fonológica das crianças e, também, facilita o processo de leitura e de escrita. No entanto, requer para o seu uso um planejamento adequado prévio com objetivos definidos. Com base nisso, sugere-se, nesta pesquisa, um trabalho com base na gamificação, para fases iniciais do ensino fundamental. São atividades elaboradas com o auxílio de jogos digitais educativos com a finalidade de desenvolver a consciência fonológica das crianças, contribuindo, ao mesmo tempo, para a aquisição da leitura e da escrita. Conclui-se que a gamificação é um importante recurso facilitador, para o processo de ensino e aprendizagem.

Palavras-chave: Consciência fonológica, Gamificação na Educação, Processo inicial de alfabetização.

\section{INTRODUÇÃO}

As tecnologias digitais têm trazido muitas mudanças para nossa realidade, não somente nas relações sociais, mas também na forma de interação no ambiente escolar. Segundo Rojo (2009, apud VIEIRA, 2013, p. 1), "[...] os gêneros emergentes dessas tecnologias colocam em foco a necessidade de se rediscutir questões relativas à leitura, uma vez que os textos que circulam socialmente são multissemióticos, ou seja, exploram um conjunto de signos e linguagens".

A tecnologia já faz parte do dia a dia, e fazer o seu uso adequado na educação pode proporcionar resultados expressivos para os alunos, em razão de se viver em uma sociedade digitalizada.

Os estudantes das novas gerações já estão inseridos nesse mundo digital, isso significa que a maioria deles nunca conheceu o mundo sem internet, celular, Google ou redes sociais.

RC: 98312

Disponível em:

https://www.nucleodoconhecimento.com.br/educacao/desenvolvimento-daconsciencia 
Para Reis (2010, apud SILVA, 2015, p. 32), o conceito de Tecnologia Educacional abrange a informática,

[...] mas não se restringe a ela. Inclui também o uso da televisão, vídeo, rádio e até mesmo cinema na promoção da educação. Entende-se tecnologia como sendo o resultado da fusão entre ciência e técnica. [...] o conceito de tecnologia educacional pode ser enunciado como 0 conjunto de procedimentos (técnicas) que visam "facilitar" os processos de ensino e aprendizagem com a utilização de meios (instrumentais, simbólicos ou organizadores) e suas consequentes transformações culturais.

O uso da tecnologia, como instrumento para construção criativa do conhecimento, possibilita ao estudante oportunidades de mudança em sua postura, de se interessar pelo seu próprio aprendizado, tornando-se crítico. No entanto, isso somente é possível se o professor estiver preparado "digitalmente". (MACHADO; LIMA, 2017).

A gamificação é uma das tecnologias educacionais que vem se destacando, que consiste em utilizar elementos de jogos digitais. Segundo Fernandes e Ribeiro (2018), o termo gamificação começou a ser usado em meados de 2010, significando basicamente "[...] utilizar os fundamentos dos jogos em atividades fora do contexto de jogo".

Kapp (2012, apud SIGNORI; GUIMARÃES; CORRÊA, 2018) define gamificação como sendo "[...] o uso de mecânicas, estética e pensamento dos games para envolver pessoas, motivar a ação, promover a aprendizagem e resolver problemas".

Alves (2009) ressalta as comunidades de aprendizagem que se formam em torno dos jogos. Para a pesquisadora:

[...] a aprendizagem que é construída em interação com os games não se constitui em uma mera cópia mecânica das situações vivenciadas, mas na ressignificação que os jogadores fazem das imagens e ações presentes nos conteúdos dos jogos eletrônicos, mediante os seus modelos de aprendizagem construídos ao longo da sua estruturação como sujeito.

RC: 98312

Disponível em:

https://www.nucleodoconhecimento.com.br/educacao/desenvolvimento-da- 
Nesse sentido, e sabendo que o processo inicial de alfabetização é importante na vida dos alunos, a prática de determinadas técnicas influencia positivamente esse exercício.

Dessa forma, nesta pesquisa, busca-se trabalhar a consciência fonológica por meio da gamificação, dado que a sua formação se dá a partir do desenvolvimento de habilidades.

Levando em consideração esse contexto, Morais (2012, p, 84) assim se manifesta:

Hoje existe um relativo consenso de que aquilo que chamamos "consciência fonológica" é, na realidade, um grande conjunto ou uma "grande constelação" de habilidades de refletir sobre os segmentos sonoros das palavras. A consciência fonológica não é uma coisa que se tem ou não, mas um conjunto de habilidades que variam consideravelmente. (MORAIS, 2012, p, 84).

A consciência fonológica na alfabetização deve ser desenvolvida de forma a contribuir com o aprendizado da leitura e da escrita. Além da criança aprender os sons que compõem as sílabas, a palavra, a frase, há estudos, com os objetivos de desenvolver em crianças a consciência fonológica, que demonstraram "[...] que também na ortografia da língua portuguesa, a consciência fonológica é um prérequisito para a aquisição de leitura e escrita (CAPOVILLA; CAPOVILLA, 1997; CAPOVILLA; CAPOVILLA; SILVEIRA, 1998, apud LOPES, 2004).

Nesta pesquisa, desenvolveu-se uma proposta de intervenção com objetivo de aplicar uma tecnologia educacional que estimule o desenvolvimento da consciência fonológica de forma lúdica, utilizando jogos digitais de modo a permitir que as crianças brinquem com as palavras.

Ensinar com o uso de jogos, desperta um interesse maior na criança, desenvolvendo a sua autonomia e participação mais efetiva no processo de alfabetização inicial. $O$ uso de jogos digitais com a finalidade de desenvolver a consciência fonológica melhora o aprendizado, ao lidar com imagens, cores e sons, o game explora o universo perceptivo da criança, fazendo com que ao longo das atividades propostas

RC: 98312

Disponível em:

https://www.nucleodoconhecimento.com.br/educacao/desenvolvimento-daconsciencia 
a criança se utilize dos seus sentidos e raciocínio para dar conta dos desafios propostos pelo jogo.

Nesse caso, percebe-se então que "[...] a revolução tecnológica produziu uma geração que cresceu em ambientes ricos de multimídias, com expectativas e visão de mundo diferente de gerações anteriores, portanto, a revisão das práticas educacionais é condição para que possamos dar-lhes educação". (SANTOS; CRUZ; PAZZETO, 2007, p. 01).

Compreendendo a importância desse recurso, pode-se transformar as aulas em um ambiente um pouco mais divertidas e mais lúdicos, chamar mais a atenção das crianças, para o conteúdo e, se explorado em sala de aula, além de diagnosticar as dificuldades individuais, facilita a mudança de estratégia, para sanar as dificuldades adequadamente. Os jogos educacionais digitais podem promover um ambiente de aprendizagem atraente, quando planejado adequadamente, para alcançar os seus objetivos, posto que se trata de um recurso importante para o desenvolvimento integral da criança.

Como se pode observar, a Tecnologia Educacional pode estar presente, na educação, de diversas maneiras e práticas como, neste caso, a gamificação. Diante disso, apresenta-se o problema norteador desta pesquisa: como a gamificação pode auxiliar as crianças na formação da consciência fonológica, no ciclo alfabetizador? Conseguintemente, o objetivo geral deste trabalho que é compreender como a gamificação pode auxiliar as crianças na formação da consciência fonológica, no ciclo alfabetizador. Foram elaborados os seguintes objetivos específicos: a) pesquisar sobre alfabetização, consciência fonológica e tecnologia educacional; b) verificar a importância do desenvolvimento da consciência fonológica, no processo inicial de alfabetização; c) explicar de que forma a gamificação pode contribuir para o desenvolvimento fonológico; e d) elaborar proposta de trabalho, baseado na gamificação, para aplicação no processo de alfabetização.

RC: 98312

Disponível em:

https://www.nucleodoconhecimento.com.br/educacao/desenvolvimento-daconsciencia 
Isso posto, entende-se que este artigo pode contribuir para o desenvolvimento da consciência fonológica, no processo inicial de alfabetização, conforme proposta de trabalho que ora se apresenta, baseada na gamificação.

Esta pesquisa é de natureza básica[3]. Em relação ao nível, caracteriza-se como uma pesquisa exploratória, com abordagem qualitativa. No que diz respeito aos procedimentos técnicos para coleta de dados, caracteriza-se como pesquisa bibliográfica.

O referencial teórico foi organizado em três capítulos, sendo eles: o processo inicial de alfabetização; desenvolvimento da consciência fonológica; e tecnologia educacional, a gamificação. Toda a discussão teórica foi realizada a partir de autores como: como Soares (2016), Morais (2012), Rojo (2013), Alves; Minho e Diniz (2014) Piccoli e Camini (2012), Capovilla e Capovilla (2000) e os documentos Currículo Base do Território Catarinense, Base Nacional Comum Curricular, CIEB, entre outros.

A análise dos dados é realizada de modo dialógico e considerando os autores que dão sustentação a essa pesquisa.

Em relação à estrutura, este texto está assim organizado: i) processo inicial de alfabetização; ii) consciência fonológica; iii) tecnologia educacional: gamificação; iv) proposta de trabalho sobre o desenvolvimento da consciência fonológica, por meio da gamificação, no início do processo de alfabetização e reflexões a partir de jogos digitais; e v) considerações finais, em seguida, as referências.

\section{PROCESSO INICIAL DE ALFABETIZAÇÃO}

Conforme a Proposta Curricular do Estado de Santa Catarina:

No aprendizado do sistema de escrita alfabética, ou mesmo antes dele, é fundamental que os estudantes interajam por meio da escrita em contextos sociointeracionais em que possam construir sentidos nas relações com o outro, mediadas pela escrita, quer o professor atue como escriba e leitor, quer

RC: 98312

Disponível em:

https://www.nucleodoconhecimento.com.br/educacao/desenvolvimento-daconsciencia 
as crianças já consigam usar a escrita de modo mais autônomo e menos heterônomo. Importa, pois, que os processos de ensino considerem que o progressivo domínio do sistema de escrita alfabética tem de se dar nos/para os/em favor dos usos sociais da escrita, no âmbito dos gêneros do discurso. (SANTA CATARINA, 2014, p. 123-124).

Na primeira infância, a criança precisa ser criança, acredita-se que o exercício que mais se adapta ao processo de aprendizagem, consiste em apresentar uma didática que estimule a curiosidade das crianças por meio de atividades lúdicas e sensoriais.

É recomendado que, nessa didática, contenham materiais que apresentem, informalmente, o início da escrita, ou seja, gêneros discursos que envolvam as crianças de modo que sejam interessantes para elas, considerando que a criança está vivenciando um processo de letramento, devendo ocorrer de forma articulada, alfabetizar letrando.

Isso pode acontecer com o uso de gêneros discursivos do universo da da literatura infantil e da cultura lúdica. Nessa perspectiva, introduzir a criança no mundo da escrita, de acordo com suas condições e sua idade. Alfabetização e letramento são processos que devem ser desenvolvidos de forma conjunta, dado que são dois processos que não se dissociam.

O termo letramento, segundo Rojo (2009, apud SANTOS; YAMAKAWA, 2017, p. 8687),

[...] busca recobrir os usos e práticas sociais de linguagem que envolvem a escrita de uma ou de outra maneira, sejam eles valorizados ou não valorizados, locais ou globais, recobrindo contextos sociais diversos (família, igreja, trabalho, mídias, escola etc.), numa perspectiva sociológica, antropológica e sociocultural.

Dessa forma, é muito importante que exista um equilíbrio entre a etapa inicial de alfabetização e o seu desenvolvimento. Segundo o Currículo Base do Território Catarinense (2019, p. 148), "[...] Assim isso implica considerar que ao ingressar no Ensino Fundamental, as crianças de seis anos necessitam se expressar por meio de 
múltiplas linguagens, e as brincadeiras, a imaginação e a fantasia constituem seus modos de ser e viver no mundo".

À vista disso, durante o processo de alfabetização e, no Ensino Fundamental, anos iniciais, é importante que o professor planeje e considere o tempo certo da apropriação da leitura e da escrita. Um ponto importante é sobre o tempo aproximado para a alfabetização, há uma ponte entre os dois segmentos. "É preciso compreender que ambos estão interligados, portanto, nos anos iniciais do Fundamental será possível intensificar e estruturar as experiências com a língua oral e escrita iniciadas na Educação Infantil”. (ROSI, [201-]).

Magda Soares, em entrevista para Nova Escola (2017) sobre Alfaletrar: alfabetização e letramento, afirma que para criança aprender a ler e escrever em um sistema de representação que é subjetivo, por se tratar de representar os sons da fala em grafias, riscos e traços, a criança precisa descobrir esse sistema vivenciando esse processo. Para que ela vivencie esse processo é necessário que o professor o entenda e compreenda como ele se desenvolve na criança, de forma que construa esse conhecimento.

Ainda, em sua fala, a autora Magda Soares explica para que o professor compreenda isso é necessário que ele tenha fundamentos psicológicos, fundamentos fonológicos[4], fundamentos linguísticos e fundamentos sociolinguísticos.

Sobre alfabetização e letramento, a Base Nacional Comum Curricular apresenta:

É importante reiterar que o processo de alfabetização e letramento, em uma perspectiva mais ampla, ocorre ao longo do percurso formativo e precisa ser compromisso de todas as áreas e de todos os componentes curriculares; dessa maneira, todos devem trabalhar considerando o texto como articulador da prática pedagógica, os diferentes gêneros discursivos como estratégia de ensino, como meio para elaborar suas sínteses. Nessa lógica, entende-se que quanto mais os sujeitos ampliam suas aprendizagens, elaboram e reelaboram conhecimentos/desenvolvem o pensamento complexo, mais alfabetizados e letrados eles se tornam. (BRASIL, 2017, p. 154).

RC: 98312

Disponível em:

https://www.nucleodoconhecimento.com.br/educacao/desenvolvimento-da- 
Nesse sentido, quando se fala em alfabetização e letramento em sentido amplo, quer dizer que ocorre durante todo o percurso formativo da criança. A alfabetização é o processo de aprendizagem do sistema de representação dos sons da fala, ou seja, sobre como se transforma os sons da fala em letras e grafemas. O letramento é o processo que desenvolve as habilidades de uso da escrita, num contexto social e cultural em que as pessoas vivem. Os dois processos, embora distintos, com bases cognitivas e linguísticas específicas, devem ser trabalhados pelos professores de forma concomitante.

Pode-se definir letramento como:

[...] estado em que vive o indivíduo que não só sabe ler e escrever, mas exerce as práticas sociais de leitura e escrita que circulam na sociedade em que vive: saber ler e lê jornais, revistas, livros, saber ler e interpretar tabelas, quadros, formulários, sua carteira de trabalho, suas contas de água, luz, telefone, saber escrever e escreve cartas, bilhetes, telegramas sem dificuldade, sabe preencher um formulário, sabe redigir um ofício, um requerimento. São exemplos das práticas mais comuns e cotidianas de leitura e escrita, muitas outras poderiam ser citadas. (SOARES, 2000, p. 2).

A criança se alfabetiza num contexto de letramento e se letra ao mesmo tempo que se alfabetizando. É importante que os alfabetizadores trabalhem esse processo, respeitando as especificidades de cada um deles. A criança, aos poucos, vai identificando o que a língua escrita representa, vai fazendo as descobertas das letras associadas aos sons, ou seja, toma dos sons das palavras.

Método é um caminho, em direção à criança alfabetizada, e se, para trilhar um caminho, é necessário conhecer seu curso, seus meandros, as dificuldades que se interpõem alfabetizares (as) dependem do conhecimento dos caminhos da criança dos processos cognitivos e linguísticos de desenvolvimento e aprendizagem da língua escrita- para orientar seus próprios passos e os passos das crianças - é o que se denominou alfabetizar com método: alfabetizar conhecendo e orientando com segurança o processo de alfabetização, o que se diferencia fundamentalmente de alfabetizar trilhando caminhos predeterminados por convencionais métodos de alfabetização. (SOARES, 2016, p. 352).

Conforme o Currículo Base do território Catarinense, é objetivo do estado que todas as crianças sejam alfabetizadas, entre o primeiro e o segundo ano do Ensino

RC: 98312

Disponível em:

https://www.nucleodoconhecimento.com.br/educacao/desenvolvimento-da- 
Fundamental. Alfabetização, nesse sentido, é: o domínio da escrita pela criança (fonemas e grafemas); o conhecimento da função que esse código adquire na formação de palavras; e o seu uso nas interações verbais. Em virtude da complexidade desse processo de aquisição da escrita e da leitura pela criança, diversas abordagens metodológicas podem ser utilizadas.

Com a chegada das crianças aos seis anos de idade no ensino fundamental, é muito importante que o professor disponibilize instrumentos pedagógicos e construa um ambiente alfabetizador adequado, para o desenvolvimento das capacidades e habilidades de cada aluno, buscando alternativas que reflitam sobre suas práticas, com objetivo de possibilitar a aprendizagem, levando em consideração a realidade de cada um.

Além de todo cuidado ao utilizar metodologias que contribuam e estimulem a compreensão e o aprendizado do aluno, nesse processo inicial de alfabetização, a criança necessita de apoio e orientação de um adulto para aprender. É necessário que o professor conheça a realidade do aluno com o objetivo de contribuir, para uma alfabetização significativa, uma vez que, no processo de alfabetização, as interações entre professores, família e alunos fazem a diferença. A ajuda da a família é de fundamental importância, para se alcançar os objetivos de aprendizagem. Família e escola devem seguir uma direção em conjunto, com os mesmos princípios e critérios.

Deve-se considerar os sentimentos de cada criança, como essencial para o desenvolvimento do processo educativo e de elaboração do conhecimento, atentando-se para a especificidades de cada criança e lembrando que todo esse processo inicial de alfabetização envolve um trabalho docente comprometido com a aprendizagem das crianças.

$\mathrm{Na}$ sequência, discorrer-se sobre como acontece o desenvolvimento da consciência fonológica[5], no processo inicial de alfabetização. 


\section{DESENVOLVIMENTO DA CONSCIÊNCIA FONOLÓGICA}

A Base Nacional Comum Curricular traz que é nos anos iniciais que é esperado que a criança se alfabetize, conforme pode ser visto:

Embora, desde que nasce e na Educação Infantil, a criança esteja cercada e participe de diferentes práticas letradas, é nos anos iniciais ( $1^{\circ}$ e $2^{\circ}$ anos) do Ensino Fundamental que se espera que ela se alfabetize. Isso significa que a alfabetização deve ser o foco da ação pedagógica. Nesse processo, é preciso que os estudantes conheçam o alfabeto e a mecânica da escrita/leitura processos que visam a que alguém (se) torne alfabetizado, ou seja, consiga "codificar e decodificar" os sons da língua (fonemas) em material gráfico (grafemas ou letras), o que envolve o desenvolvimento de uma consciência fonológica (dos fonemas do português do Brasil e de sua organização em segmentos sonoros maiores como sílabas e palavras) e o conhecimento do alfabeto do português do Brasil em seus vários formatos (letras imprensa e cursiva, maiúsculas e minúsculas), além do estabelecimento de relações grafofônicas entre os dois sistemas de materialização da língua. (BRASIL 2017, p.89).

Ao trazer para a sala de aula situações lúdicas de aprendizagem, torna-se necessário associar também com as experiências vivenciadas, na Educação Infantil. Tal associação deve prever não só a sistematização progressiva dessas experiências pelos alunos, como também outras maneiras de se relacionarem com o mundo. (BRASIL, 2017).

É imprescindível que se apresente aos alunos outras oportunidades de leituras,

[...] de formular hipóteses sobre os fenômenos, de testá-las, de refutá-las, de elaborar conclusões, em uma atitude ativa na construção de conhecimentos. Nesse período da vida, as crianças estão vivendo mudanças importantes, em seu processo de desenvolvimento que repercutem em suas relações consigo mesmas, com os outros e com o mundo. (BRASIL, 2017, p. 58).

Ao entrar no ensino fundamental, a criança passa para o processo inicial de alfabetização, podendo ainda trabalhar com metodologias lúdicas, mas com metas definidas, para que a criança aprenda a leitura e a escrita.

Algumas pesquisas comprovam que nesse processo é preciso fazer com que criança entenda que as palavras têm uma representação fonética, ou seja, as letras

RC: 98312

Disponível em:

https://www.nucleodoconhecimento.com.br/educacao/desenvolvimento-daconsciencia 
têm sons, a esse processo chama-se de consciência fonológica. Em outras palavras, as crianças precisam ter conhecimento de que a língua, quando falada, pode ser dividida em componentes distintos, isto é, pode-se dividir uma frase em palavras; por sua vez, as palavras podem ser segmentadas em sílabas. As sílabas podem ser divididas em fonemas.

As crianças alfabetizadas com o método fônico aprendem, desde cedo, qual a forma adequada de se pronunciar a língua portuguesa. Por se tratar de um método que destaca a oralidade, os alunos crescem em um ambiente em que a fala e a escrita são realizadas de maneira apropriada à comunicação.

Alfabetizar é:

[...] trabalhar com a apropriação pelo aluno da ortografia do português do Brasil escrito, compreendendo como se dá este processo (longo) de construção de um conjunto de conhecimentos sobre o funcionamento fonológico da língua pelo estudante. Para isso, é preciso conhecer as relações fono-ortográficas, isto é, as relações entre sons (fonemas) do português oral do Brasil em suas variedades e as letras (grafemas) do português brasileiro escrito. Dito de outro modo, conhecer a "mecânica" ou o funcionamento da escrita alfabética para ler e escrever significa, principalmente, perceber as relações bastante complexas que se estabelecem entre os sons da fala (fonemas) e as letras da escrita (grafemas), o que envolve consciência fonológica da linguagem: perceber seus sons, como se separam e se juntam em novas palavras etc. (BRASIL, 2017, p 90).

As atividades que envolvem a consciência fonológica contribuem para o aprendizado inicial da escrita, podendo ser uma forma de desenvolver-se o gosto pela leitura. Essas atividades podem ser planejadas de forma lúdica, desde que bem elaboradas, com o propósito de criar situações em que a criança pense, reflita e expresse os sons da fala, relacionando-as com as letras e representando-as de formas gráficas. Isso favorece o esse processo de alfabetização, também, sinaliza eventuais problemas de aprendizagem. 
Estudos evidenciam a importância da consciência fonológica para aprendizagem da língua escrita, já que para a criança aprender ler e escrever, no sistema de escrita é necessário à percepção grafofônemica.

Segundo Piccoli e Camini, (2012, p. 103):

A consciência fonológica pode ser agrupada como um conjunto de habilidades que permite à criança compreender e manipular unidades sonoras da língua, conseguindo segmentar unidades maiores em menores. Tais capacidades são fundamentais na alfabetização, tendo em vista que da consciência fonológica depende da série de processos fundamentais para a aprendizagem da leitura e da escrita. (PICCOLI; CAMINI, 2012, p. 103).

A consciência fonológica prepara a criança, para o processo de decodificação da língua por meio do estudo de grafemas, sons, sílabas e palavras adquiridas pela criança de maneira formal ou informal, iniciando-se pela oralidade.

Magda Soares, no portal Ceale (Centro de alfabetização, leitura e escrita), na seção Magda Soares Responde (2015) afirma que,

[...] quando se fala em consciência fonológica, fala-se de um conjunto que envolve: a consciência do som da palavra, de partes iguais das palavras (rima e aliteração), da segmentação da palavra em partes, de consciência silábica e finalmente de consciência fonêmica. É um processo de desenvolvimento da criança que ocorre conjugando à aprendizagem das letras com a correspondência delas os fonemas, o que depende do desenvolvimento da consciência fonológica, em seus vários níveis. (CEALE, 2015, n.p.).

Os exercícios que objetivam trabalhar com a fonologia, elaborados pelos professores, para a sala de aula com as crianças, nesse processo inicial de alfabetização, contribuem de maneira significativa. Mas importa considerar que é preciso criar a necessidade na criança, para que ela queira aprender. Assim, para esses exercícios faz-se necessário partir de uma situação que desencadeie essa necessidade nas crianças.

Essas atividades devem contemplar as habilidades que se deseja trabalhar, a exemplo, a reflexão, identificação e manipulação dos sons presentes, em nossa língua.

RC: 98312

Disponível em:

https://www.nucleodoconhecimento.com.br/educacao/desenvolvimento-daconsciencia 
Segundo Capovilla e Capovilla (2000b), o procedimento, para desenvolver consciência fonológica e ensinar correspondências grafo-fonêmicas, abrange diversos níveis de consciência, desde a consciência de rimas e aliterações até a consciência de fonemas.

Segundo a Base Nacional Comum Curricular,

[...] o contato com histórias, contos, fábulas, poemas, cordéis etc. propicia a familiaridade com livros, com diferentes gêneros literários, a diferenciação entre ilustrações e escrita, a aprendizagem da direção da escrita e as formas corretas de manipulação de livros. Nesse convívio com textos escritos, as crianças vão construindo hipóteses sobre a escrita que se revelam, inicialmente, em rabiscos e garatujas e, à medida que vão conhecendo letras, em escritas espontâneas, não convencionais, mas já indicativas da compreensão da escrita como sistema de representação da língua. (BRASIL, 2017, p. 118).

Compreende-se então que para desenvolver a consciência fonológica, o professor pode usar sua criatividade e alinhar situações lúdicas com a prática pedagógica, levando para as crianças parlendas, cantigas, trava língua etc. Também pode trabalhar com jogos de consciência fonológica, cuja finalidade seja para que os alunos consigam refletir sobre o que se fala e o que se escreve, de forma que consigam explorar a dimensão sonora da língua. O professor pode usar estratégias com o objetivo de proporcionar situações em que a criança pense e reflita sobre os sons da fala, para futuramente poder relacioná-los com as letras e representá-las.

Dito isso, entende-se que a criança aprende a ler e escrever, quando ela tem consciência de alguns processos fonológicos, e o professor pode contribuir, para esse processo, utilizando as tecnologias educacionais.

Em seguida, apresenta-se -a tecnologia educacional, em específico a este estudo, a gamificação, de que forma poderá contribuir, para o desenvolvimento da consciência fonológica, no processo inicial de alfabetização. 


\title{
4. TECNOLOGIA EDUCACIONAL: GAMIFICAÇÃO
}

Com as tecnologias de informação e comunicação (TICs) tornando-se cada vez mais acessíveis, transforma-se também a sociedade.

\begin{abstract}
A sociedade vem passando por mudanças profundas: por meio dos smartphones, por exemplo, as pessoas se conectam a tudo que está à sua volta, pesquisando, assistindo, comprando, jogando, relacionando-se, aprendendo, investindo, entre tantas outras atividades. Esses aparelhos integram em um único dispositivo funções que, pouco a pouco, vão se tornando indispensáveis para as pessoas. Gradativamente, robôs e a inteligência artificial surgem em nosso cotidiano, e não apenas como objetos de filmes de ficção científica ou de empresas de tecnologia; recursos tecnológicos, como impressoras 3D, fabricam casas, próteses, órgãos humanos e estão cada dia mais acessíveis. Além disso, o universo da tecnologia nos permite: organizar uma viagem usando apenas um celular, criar ferramentas próprias ou romper com os modelos mais tradicionais de trabalho, de comunicação, de educação etc. É visível o direcionamento para uma sociedade mais colaborativa e para uma cultura de compartilhamento e construção coletiva, seja no mundo real ou no virtual. (CIEB, 2018, P.14).
\end{abstract}

Os avanços tecnológicos conquistaram as novas gerações; os estudantes da atualidade são nativos digitais, ou seja, eles nasceram em mundo onde a internet já estava presente na vida cotidiana das pessoas; se esta conectados no mundo virtual praticamente durante todo o dia[6].

Isso fez com que houvesse uma constante transformação entre a comunicação da escola com o aluno. Para que haja uma conexão verdadeira entre os estudantes das novas gerações e professores, o processo de ensino aprendizagem necessita levar em consideração o uso da tecnologia, como uma grande aliada do ensino. Partindo dessa necessidade, destaca-se a tecnologia educacional, especialmente para trazer a inovação e facilitar o processo de ensino aprendizagem[7].

Conforme pode ser visto:

O termo tecnologia educacional remete a recursos tecnológicos para apoiar e aprimorar o ensino e a aprendizagem, promovendo desenvolvimento socioeducativo dos alunos e acesso à informação. Por sua vez, a ciência da computação, com suas áreas e subáreas, está contemplada, na medida em

RC: 98312

Disponível em:

https://www. nucleodoconhecimento.com.br/educacao/desenvolvimento-daconsciencia 
que estuda técnicas, metodologias, instrumentos computacionais, busca soluções para problemas etc. (CIEB, 2018, p. 17).

Com iniciativas inovadoras, os professores podem transformar as tecnologias educacionais em metodologias ativas e motivadoras. Uma tecnologia educacional inovadora que vem chamando atenção nas escolas é a gamificação. Essa metodologia ativa é constituída através de dinâmicas de jogos digitais, cujo objetivo é utilizar a gamificação como ferramenta tecnológica, para aproximar os alunos, melhorar o aprendizado, despertar o interesse, aumentar a participação, desenvolver a criatividade.

A gamificação se constitui na utilização da mecânica dos games em cenários não games, criando espaços de aprendizagem mediados pelo desafio, pelo prazer e entretenimento. Compreendemos espaços de aprendizagem como distintos cenários escolares e não escolares que potencializam o desenvolvimento de habilidades cognitivas [...]. (ALVES; MINHO; DINIZ, 2014, p. 76).

Percebe-se, então, que o jogo digital vem se destacando, nas práticas pedagógicas, em diversas áreas do conhecimento, pois é apresentado como um recurso, para determinado conteúdo, uma vez que os jogos digitais auxiliam, para uma melhor compreensão, dado que o aluno também tem a oportunidade de aprender de uma forma mais ativa. As metodologias inovadoras mostram como a cultura digital pode atuar como um elemento transformador, no processo de ensino aprendizagem.

Da mesma forma o professor, que se vê num dilema ao colocar lado a lado seus velhos métodos e as possibilidades oferecidas pelas novas tecnologias, pode encontrar na Cultura Digital estratégias para desenvolver novas metodologias de ensino-aprendizagem que envolvam o aluno, fazendo da escola um local de pensamento sobre as possibilidades que as redes e comunidades digitais oferecem, tanto para o desenvolvimento intelectual quanto nas possibilidades de socialização e colaboração no coletivo escolar. (BRASIL, 2010, p. 1).

Pensando nessas possibilidades oferecidas pela cultura digital, pode-se usar como estratégias metodológicas o jogo digital, no processo inicial de alfabetização, elaborando aulas gamificadas, incentivando a leitura e a escrita através da gamificação.

RC: 98312

Disponível em:

https://www.nucleodoconhecimento.com.br/educacao/desenvolvimento-da- 
Procure fazer parcerias com os espaços de pesquisa de sua cidade, de seu estado. Veja na internet as Instituições e suas atividades de extensão junto às comunidades e converse com eles sobre as possibilidades de incluir sua escola neste trabalho inovador. Pontos de Culturas para edição de áudio, vídeo, etc., jogos de estratégia, jogos interativos, etc., produção, distribuição e desenvolvimento de mídias livres, etc., há uma infinidade de novidades quentíssimas esperando por você e por seus monitorados em Cultura Digital: alcance-as e traga-as para sua escola. (BRASIL, 2013, p. 32).

Em meio a tantas modificações, é importante lembrar que a geração das crianças que estão nas salas de aulas, não é mais a mesma. É preciso inovar e caminhar junto na mesma velocidade da evolução tecnológica, pois as crianças nativas digitais já sabem manipular dispositivos eletrônicos e sabem a definição de gamificação.

Segundo Rojo (2013), é preciso que a instituição escolar prepare a população, para um funcionamento da sociedade cada vez mais digital, também para buscar, no ciberespaço, um lugar para se encontrar, de maneira crítica, com diferenças múltiplas.

Quando se cria um cenário lúdico através de jogos digitais, pode-se contribuir para alfabetização, em vários aspectos: trazer interação, desenvolver a consciência fonológica através de jogos que contenham exercícios como rimas; separar palavras em sílabas; identificar palavras com o mesmo som inicial, palavras ou sílabas que tenham o som final igual; contar cada som que constitui uma palavra. Enfim, existem inúmeras possibilidades de conectar as crianças com a aprendizagem escolar e com o mundo virtual, trazendo, por conseguinte, grande contribuição para o processo inicial de alfabetização.

Levando em consideração os argumentos aqui apresentados, na continuidade, passa-se para o relato das contribuições da gamificação, para o desenvolvimento da consciência fonológica no processo inicial de alfabetização. 


\section{DESENVOLVIMENTO DA CONSCIÊNCIA FONOLÓGICA, POR MEIO DA GAMIFICAÇÃO, NO INÍCIO DO PROCESSO DE ALFABETIZAÇÃO: REFLEXÕES A PARTIR DE JOGOS DIGITAIS}

Considerando as reflexões realizadas até aqui, na sequência, são apresentadas algumas sugestões de jogos digitais que podem contribuir com o desenvolvimento da consciência fonológica, no processo inicial de alfabetização. Inicia-se com uma sugestão de um plano de aula, com aplicação de jogos digitais de alfabetização, para trabalhar os tipos de sub-habilidades que fazem parte da consciência fonológica.

Os tipos de sub-habilidades da consciência fonológica, referem-se ao conhecimento da língua falada que as crianças devem ter, em relação a: palavras, sílabas, fonemas, rimas e aliterações.

Segundo PNAIC (2013), "diferentes formas linguísticas a que qualquer criança é exposta dentro de uma cultura vão formando sua consciência fonológica, dentre delas destacamos as músicas, cantigas de roda, poesias, parlendas, jogos orais e fala propriamente dita". (BRASIL, 2013, p. 4).

Partindo dessa reflexão, descreve-se aqui de maneira simplificada o significado de cada sub-habilidade. Inicia-se com a consciência das palavras que consiste em segmentar a frase, em palavras, percebendo-se a relação entre elas, organizando as palavras em uma sequência que dê sentido. A consciência silábica refere-se à habilidade de decompor a palavra em sílabas. A criança precisa identificar as sílabas e localizá-las dentro de palavras apresentadas, oralmente.

Já as rimas são reconhecidas pelas semelhanças sonoras nas palavras; as aliterações são conhecidas com a repetição de fonemas consonantais em um enunciado, os sons podem ser parecidos ou iguais e estão presente no meio e início

RC: 98312

Disponível em:

https://www.nucleodoconhecimento.com.br/educacao/desenvolvimento-daconsciencia 
da palavra. O gênero trava-línguas pode ser dado como exemplo para aliterações. As aliterações também estão presentes em poemas, músicas.

Por fim, a consciência fonêmica, última habilidade adquirida pela criança, é a capacidade de manipular sons individuais ou fonemas que compõem a palavra, as silabas, as partes das silabas e as palavras.

Seguindo com a descrição, o plano de aula tem como tema "Consciência fonológica: brincando com o som das palavras". O público-alvo são para crianças do $2^{\circ}$ ano do ensino fundamental; o tempo de duração do plano de aula proposto é de uma semana, conforme a disponibilidade da escola em que seriam aplicadas essas sugestões de atividades.

Para dar início à construção do plano de aula, buscou-se a orientação na Base Nacional Comum Curricular (BNCC), referente ao componente curricular de Língua Portuguesa, a unidade temática análise linguística/semiótica (alfabetização).

Ainda, seguindo as orientações da BNCC, os objetivos a serem trabalhados no plano de aula serão conhecimento do alfabeto do Brasil, construção dos sistema alfabético, construção do sistema da ortografia, segmentação das palavras e classificação das palavras por números e sílabas. As habilidades que serão trabalhadas, também, tiveram como fonte a Base Nacional Comum Curricular (BNCC) sendo elas:

(EF01LP04) Distinguir as letras do alfabeto de outros sinais gráficos. Construção do sistema alfabético.

(EF01LP05) Reconhecer o sistema de escrita alfabética como representação dos sons da fala.

(EF01LP06) Segmentar oralmente palavras em sílabas.

RC: 98312

Disponível em:

https://www.nucleodoconhecimento.com.br/educacao/desenvolvimento-daconsciencia 
(EF02LP02) Segmentar palavra em sílabas e remover e substituir sílabas iniciais, mediais ou finais para criar novas palavras.

(EF01LP07) Identificar fonemas e sua representação por letras.

\section{Eixo: Cultura digital}

Conceito letramento digital,

Habilidades CDO2LD01: Interagir com diferentes mídias

Depois de organizado o plano de aula, seguindo as orientações da BNCC, chegou o momento de estabelecer quais os objetivos, em relação ao plano de aula a ser desenvolvido, e o que se pretenderia alcançar com essas atividades. Decidiu-se, então, como objetivo geral: propor uma sequência de aulas, utilizando jogos digitais de modo a incentivar o desenvolvimento da consciência fonológica contribuir para o processo inicial de alfabetização.

Como objetivos específicos: realizar exercícios que possibilitem o desenvolvimento da consciência fonológica; familiarizar as crianças com a escrita, fazendo com elas consigam reconhecer palavras e associá-las com as imagens; Motivar a leitura por meio da literatura infantil, usando os livros de histórias infantis como ferramenta, no processo inicial de alfabetização; trabalhar com jogos digitais de alfabetização, fazendo com eles venham a contribuir com o desenvolvimento da consciência fonológica.

A aula iniciaria com uma literatura infantil pelo fato de que a contação de histórias ajuda as crianças a desenvolverem a consciência fonológica, de maneira divertida, possibilitando o entendimento que as palavras têm a representação fonológica.

O propósito dessa atividade de leitura é que a criança reconheça as letras do alfabeto e observe quantas palavras podem ser formadas com elas e o som que são produzidos por elas por meio da voz. Foi escolhido o livro de literatura infantil

RC: 98312

Disponível em:

https://www.nucleodoconhecimento.com.br/educacao/desenvolvimento-daconsciencia 
"Palavras, muitas palavras..." da autora Ruth Rocha, (2013). Nesse livro cada letra do alfabeto é a primeira letra de muitas palavras, todas as letras do alfabeto apresentam-se para as crianças de forma divertida e com muitas rimas. Os desenhos são coloridos e chamam a atenção das crianças para as palavras. Para realizar essa atividade, é preciso escolher um local aconchegante na escola onde a história possa ser contada com tranquilidade. Finalizando a leitura, é preciso haver interação com as crianças e professor com diálogos. Nesse momento, o professor falar com as crianças, apresentando a importância de conhecer o nome de cada letra e o seu som, para aprender a ler e escrever, e demonstrar que as letras servem para representar o som da nossa fala.

Para melhor compreensão das crianças e para que eles possam aprender de uma forma lúdica, pode ser compartilhado o vídeo musical: As letras falam de Jaime Zorzi (2017) (metodologia para alfabetização). As letras falam é uma proposta elabora pelo autor Jaime Zorzi. Segundo o autor "[...] tem como objetivo desenvolver competências fundamentais envolvidas no processo de alfabetização, dentre delas as chamadas habilidades meta fonológicas e as correspondências entre fonemas e grafemas". (ZORZI, 2017).

Encerrada essa parte do plano de aula, inicia-se com a aplicação dos jogos digitais. Dá-se o início das atividades, usando os games educativos de alfabetização.

Os Jogos digitais, apresentados a seguir, estão disponíveis em um aplicativo digital de acesso livre, conhecido como 4shared, fonte https:/www.4shared.com. Esses jogos contêm atividades que estimulam o processo inicial de alfabetização. Para esse planejamento, são aplicados cinco jogos, e cada jogo trabalhará uma subhabilidade da consciência fonológica. Precisa-se da sala de informática da escola, para instalar os jogos digitais, eles podem ser salvos em pendrives e transferidos, para outros computadores, permitindo o acesso das crianças. Deverá ser aplicado um jogo de cada vez, porque o professor precisa auxiliar as crianças, na realização das atividades que cada jogo contém. O tempo de utilização dos jogos dependerá do 
planejamento do professor, mas deve respeitar o tempo necessário, para execução de cada jogo e as especificidades de cada criança.

$\mathrm{Na}$ sequência, são descritos os jogos digitais, identificando neles cada subhabilidade da consciência fonológica que será trabalhada.

\section{Exemplo:}

Consciência das palavras:

Jogo da cascata: Cachoeira das letrinhas

Figura 1 - interface do jogo Cachoeira de letrinhas.

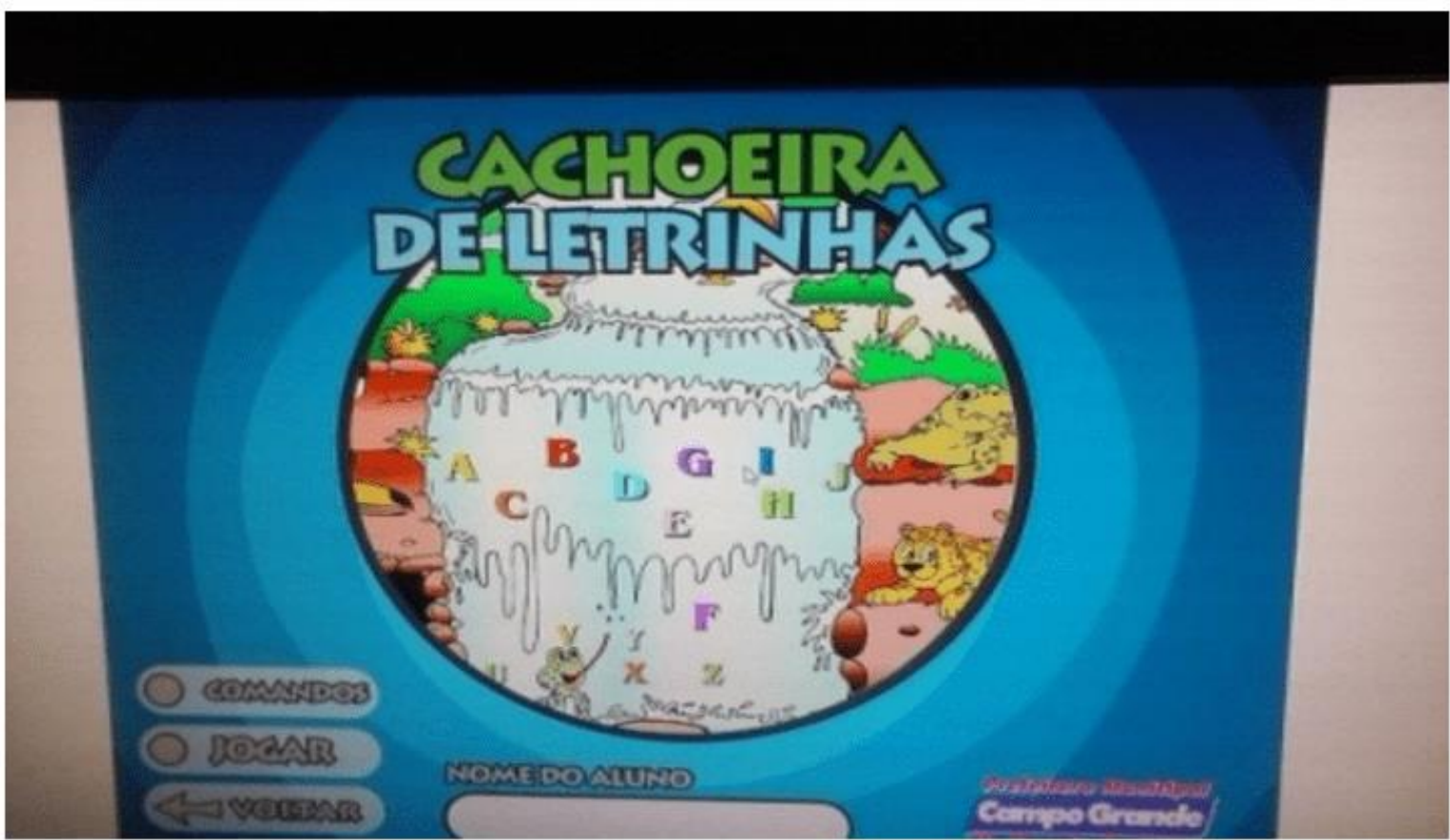

Fonte: arquivo pessoal.

Clicando em comandos, aparecerão as funções:

- Clique em jogar;

- Selecione a placa;

RC: 98312

Disponível em:

https://www.nucleodoconhecimento.com.br/educacao/desenvolvimento-daconsciencia 
- Para movimentar o sapo, na cachoeira, utilize as setas direcionais: direita e esquerda;

- Para virar o sapo, na cachoeira, utilize as setas direcionais: acima e abaixo.

O sapo fica, na cachoeira, e a criança tem que fazer o sapo engolir as letras que caem da dela, pode-se nesse jogo fazer cinco exercícios: formar palavras, separar as letras maiúsculas, separar letras consoantes, separar letras vogais e separar letras minúsculas.

2 Exemplo:

Consciência silábica

Jogo: Construindo com Letrinhas

Figura 2 - Interface do jogo Construindo com Letrinhas.

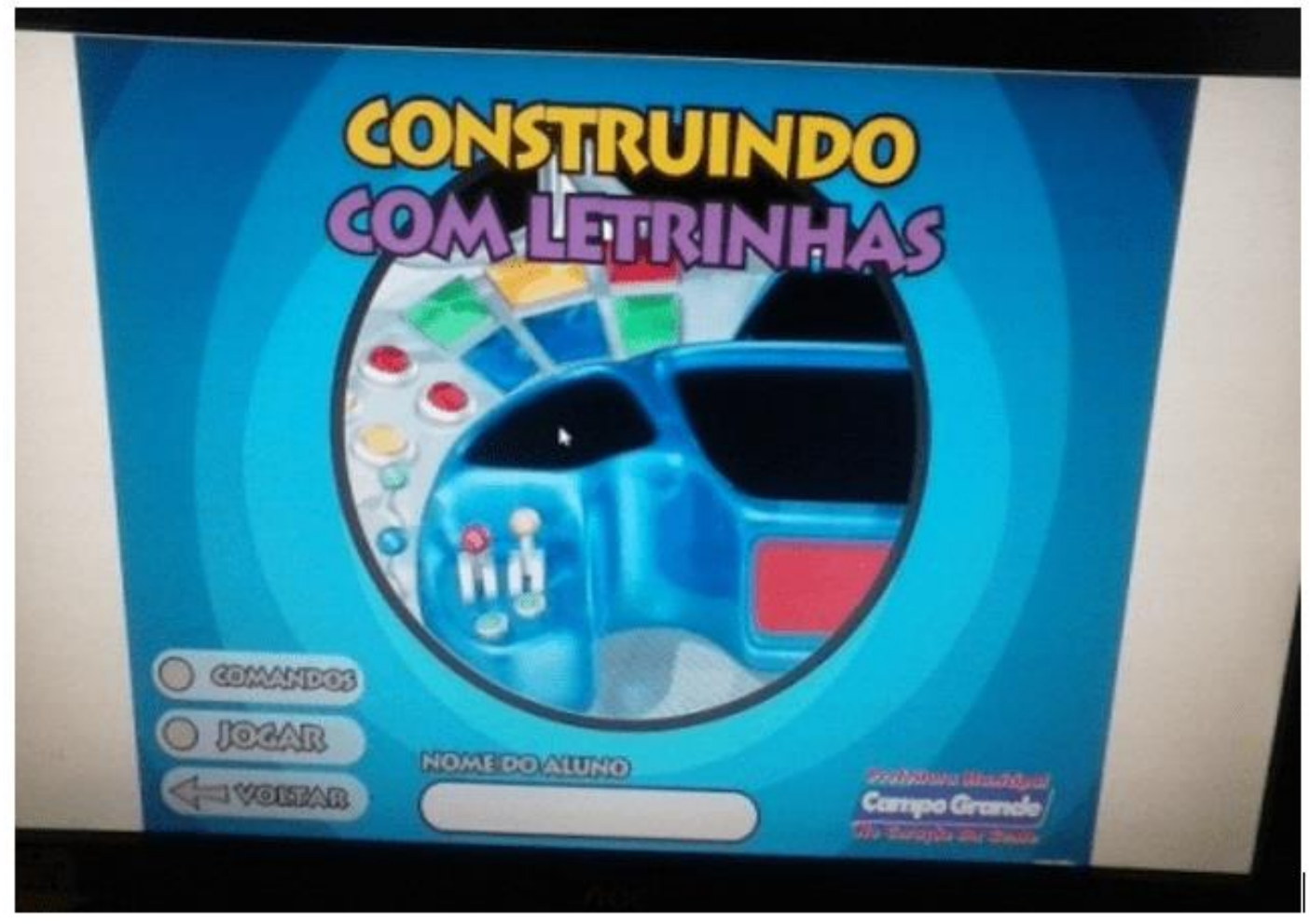

Fonte: arquivo pessoal.

RC: 98312

Disponível em:

https://www.nucleodoconhecimento.com.br/educacao/desenvolvimento-daconsciencia 
Seguindo o comando, o jogador vai clicar em:

- Jogar;

- No painel de controle, clique em atividades e escolha a atividade desejada;

- Observar o painel de controle específico;

Quando o jogo inicia, o "jogador" parece estar dentro de uma nave com som semelhante a uma nave ligada, no painel de controle da nave há as opções de atividades. Há uma história de Alda Maria do Couto: Tecendo a rede (Inédito 2002) que é a história das meninas que começam com a letra A. Nesse jogo, além da história, existem três exercícios, quais sejam: álbum de figurinhas, maiúsculas e minúsculas, próprios e comuns.

Clicando, no álbum de figurinhas, aparecerão duas opções: figura e álbum; primeiro deve-se clicar em álbum e, depois, em figurinhas. O objetivo é encontrar a figurinha e arrastá-la para o álbum, até que ele fique completo. Quando parecer uma figura que não há no álbum, existe a opção: devolução. Então, pode-se clicar novamente, para aparecerem mais figurinhas. Nesse jogo, há uma voz de comando, repetindo as palavras que aparecem na figurinha. Isso ajuda a criança a identificar o som de cada palavra. Clicando em: construindo palavras, aparecerá uma figura e você tem que escrever ao lado o nome da figura corretamente.

Ao Clicar em maiúscula e minúscula, vão aparecer dois livros com a identificação maiúscula e minúscula. Pode ser escolhido um livro e surgirão muitas palavras misturadas ao lado do painel. O objetivo é arrastá-las, adequadamente para cada livro. Clicando em próprios e comuns, surgirão balões, para que se identifique os nomes próprios e comuns. Durante todos os exercícios, há a ajuda de voz que indica como jogar e falando o nome de cada letra, para auxiliar a criança no jogo.

3 Exemplo:

Rimas e aliterações

RC: 98312

Disponível em:

https://www.nucleodoconhecimento.com.br/educacao/desenvolvimento-daconsciencia 
Jogo: No Reino da Palavras

Figura 3 - Interface do jogo No Reino da Palavras.

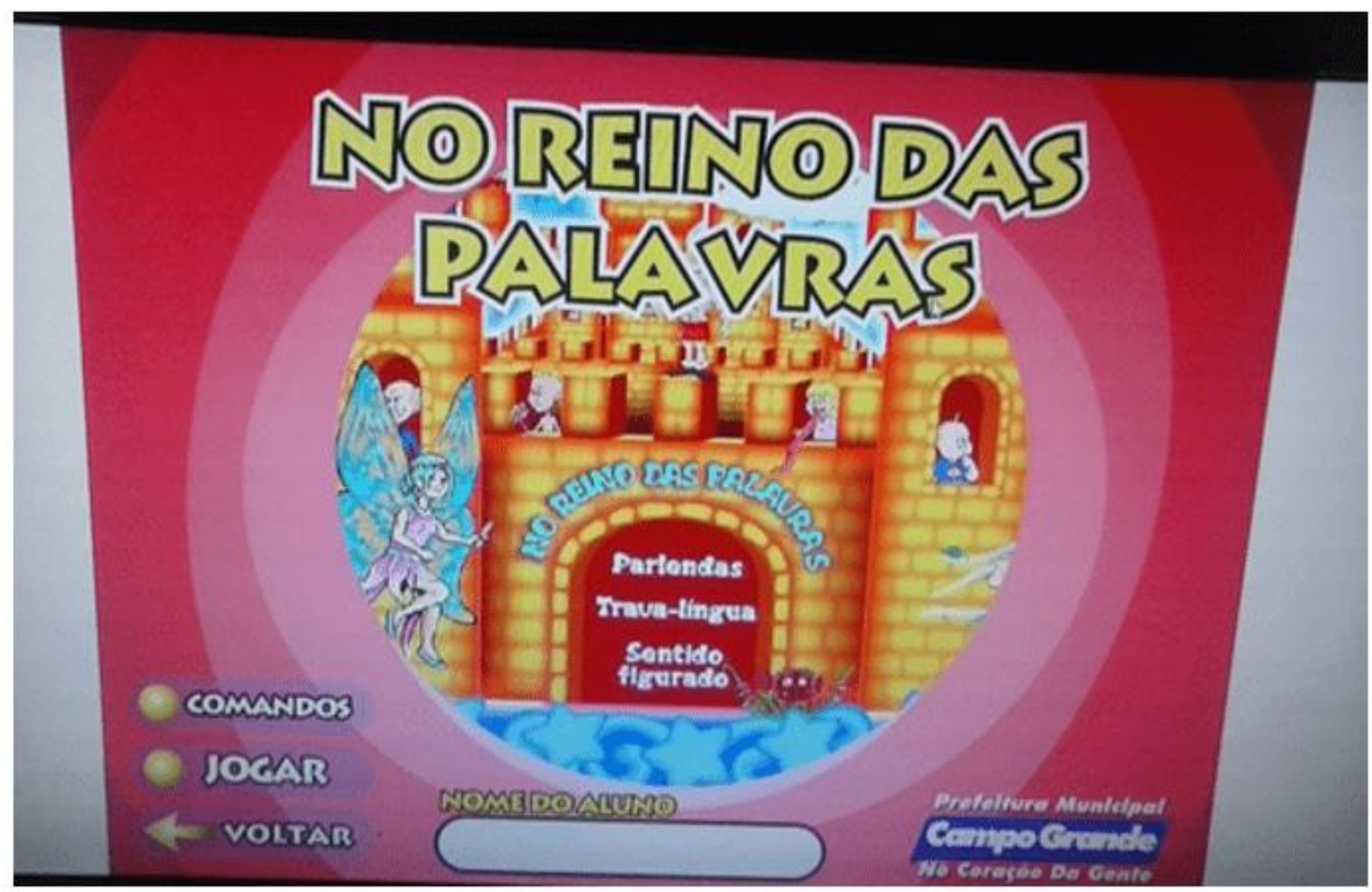

Fonte: arquivo pessoal.

Para começar a jogar, é preciso digitar o nome da criança, depois clicar em jogar.

- Escolha a opção desejada;

- Clique em menu jogar;

- Clique, em menu livro, para ter acesso aos conteúdos ou produção de textos.

Parlendas e trava línguas:

- Clique, em estrela, com o título desejado;

- Pegue o lápis e encontre, no caça-palavras, a palavra selecionada;

RC: 98312

Disponível em:

https://www.nucleodoconhecimento.com.br/educacao/desenvolvimento-da- 
- Clique, no início e no final da palavra, ouça o texto referente e clique, no botão continuar jogando.

Sentido figurado

Para melhor visualização da imagem passe o mouse sobre a figura;

- Clique, em estrela, com a opção desejada;

- Pegue o lápis e encontre o significado de sentindo figurado, no caça-palavras;

- Clique no início e final da palavra.

Esse jogo ensina de uma forma divertida as parlendas, trava-língua e sentido figurado.

O cenário do jogo é um castelo onde uma fadinha aparece explicando o que é será aprendido pela criança.

Exemplos: Rimas e Aliterações

Jogo: Brincar de Rimar

RC: 98312

Disponível em:

https://www.nucleodoconhecimento.com.br/educacao/desenvolvimento-daconsciencia 
Figura 4 - Interface do jogo Brincar de Rimar

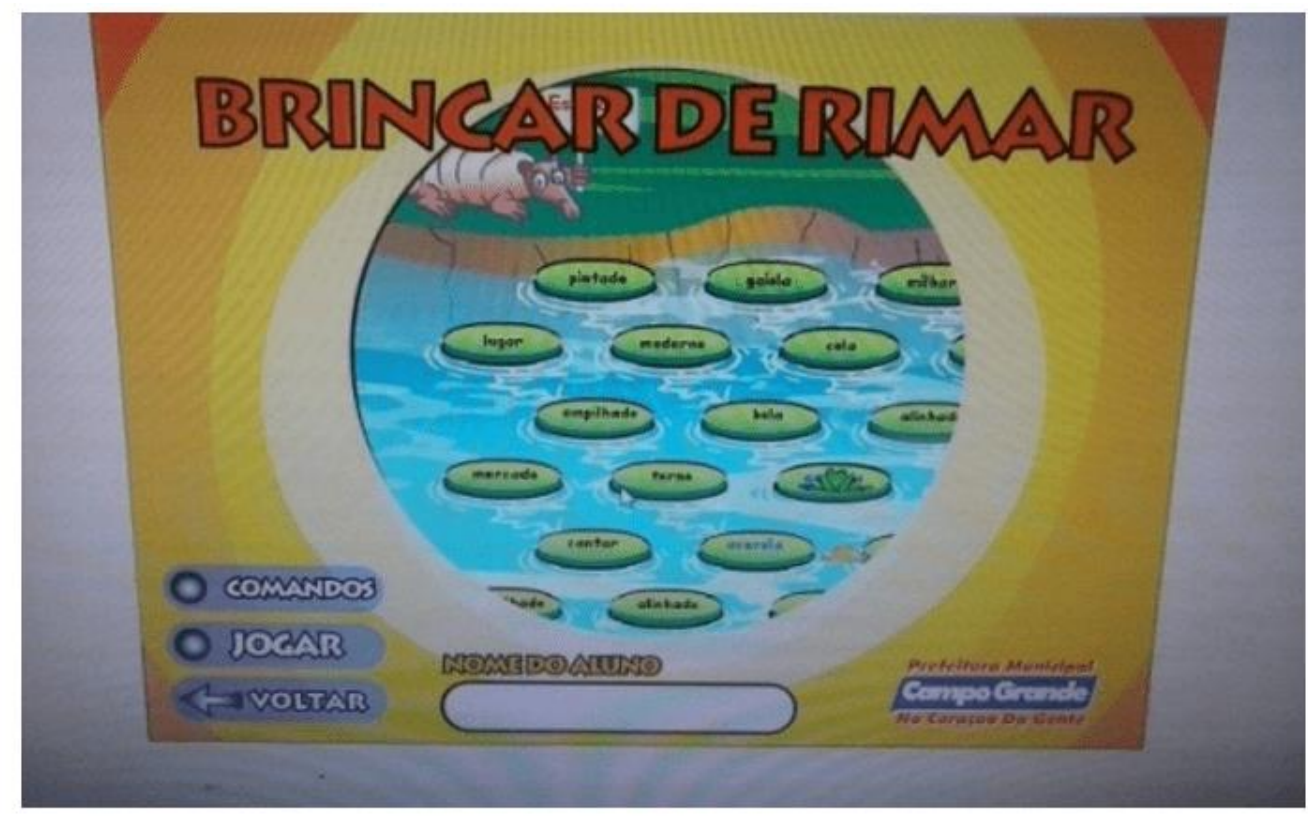

Fonte: arquivo pessoal.

Clique em Comandos:

- Leia a rima;

- Clique em jogar;

- Observe a palavra sorteada que rima com a sorteada pelo Tatu.

O Jogo começa com a rima "Lá no meio do pantanal" da autora Alda Maria Quadros Couto.

Quando se clica em jogar, aparecerá um sapinho, explicando a brincadeira, o Tatu sorteia uma palavra. O cenário do jogo é uma lagoa com vários sapinhos para atravessar, mas para isso é preciso acertar as rimas, quando as rimas são certas, o sapinho vai pulando até chegar ao outro lado, se não se acerta, o sapinho cai na lagoa. Toda vez que o sapinho conseguir chegar do outro lado da lagoa, o Tatu sorteia outra palavra, para rimar e levar o sapinho novamente para o outro lado da 
lagoa. Nesse jogo, há uma voz de comando ajudando o jogador com as pronúncias das palavras.

4 Atividade

Consciência Fonêmica

Jogo Brincando com as palavras

Figura 5 - Interface Brincando com as palavras

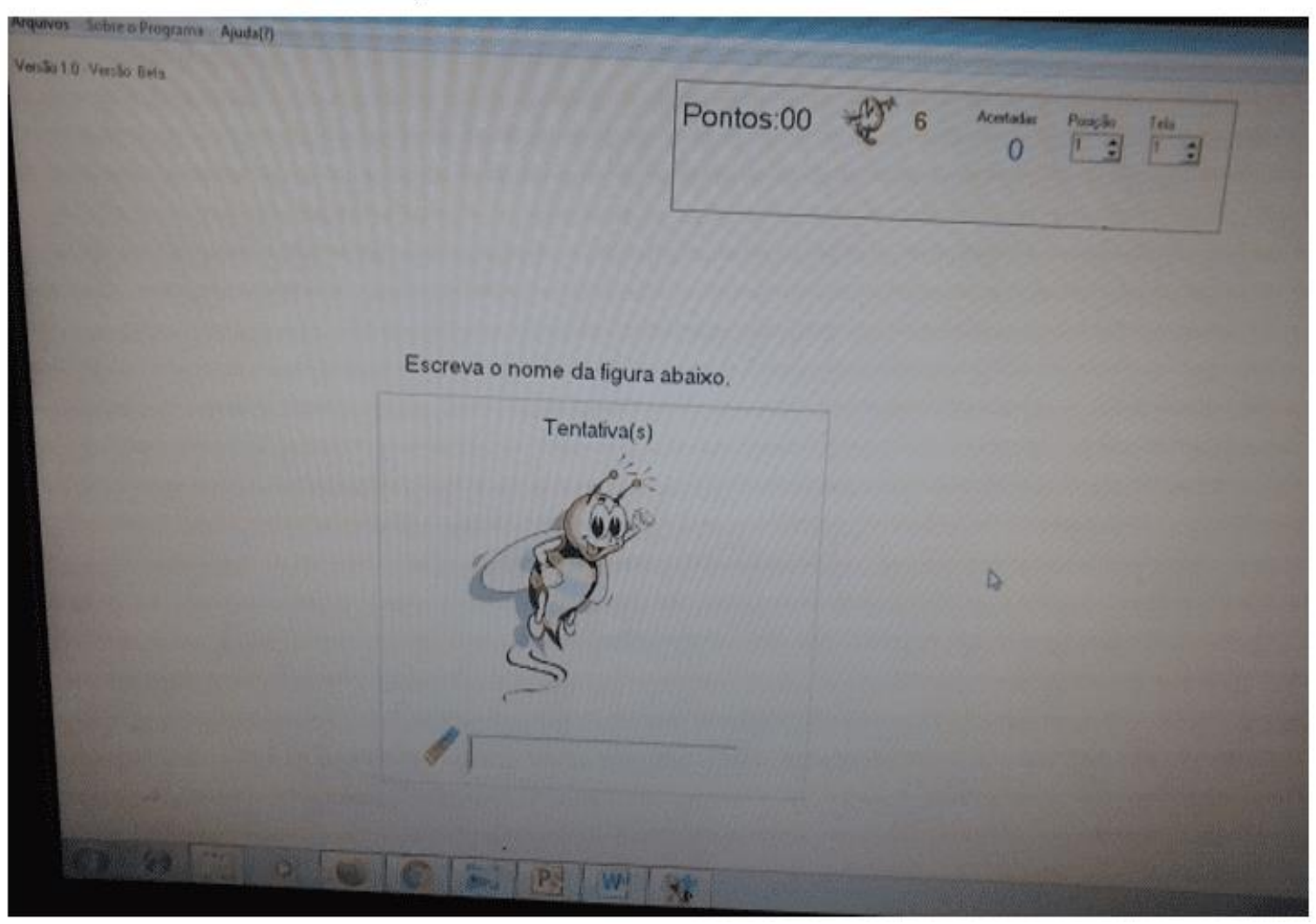

Fonte: arquivo pessoal.

Nesse jogo, a criança observa o desenho e escreve o nome adequado, quanto mais palavras ela acertar, mais pontos ela vai adquirir. Esse jogo ajudará a criança a refletir sobre o som das palavras, com isso pode-se analisara capacidade que a 
criança terá de ouvir e descobrir qual palavra está sendo dita por outra pessoa, unindo os fonemas por ela emitidos e formar novas palavras.

Encerra-se essa etapa de sugestões de jogos digitais. Entende-se que é possível trazer metodologias inovadoras como a gamificação para a sala de aula, dado que elas podem incentivar as crianças, desenvolvendo o seu aprendizado, e contribuírem positivamente, para o processo inicial de alfabetização.

\section{CONSIDERAÇÕES FINAIS}

Esse artigo trouxe como temática o desenvolvimento da consciência fonológica no ciclo alfabetizador: brincando com o som das palavras e, como objetivo, compreender de que forma a gamificação pode contribuir para o desenvolvimento da consciência fonológica, no processo inicial de alfabetização. Para alcançar esse objetivo, desenvolveu-se uma pesquisa de natureza básica e quanto aos objetivos, classifica-se como pesquisa exploratória, de abordagem qualitativa. Trata-se de uma pesquisa bibliográfica, em relação aos procedimentos técnicos de coleta de dados. A partir das leituras e reflexões de autores que embasaram esse artigo, foi possível apresentar propostas com base em uma metodologia ativa, a gamificação, de modo a desenvolver a consciência fonológica das crianças, em um ambiente em que elas possam brincar com os sons das palavras.

Ressalta-se que a gamificação tem se mostrado um excelente recurso didático, para contribuir com a educação, também para o processo inicial de alfabetização, pois é possível alfabetizar de forma lúdica desde que os objetivos sejam estabelecidos.

Refletindo sobre os conceitos de especialistas da área sobre o desenvolvimento da consciência fonológica, pode-se afirmar que o desenvolvimento da consciência fonológica é um processo fundamental para o início da alfabetização. Não se pode perder de vista, também, que esse processo deve estar articulado a diferentes situações desencadeadoras de aprendizagem e, principalmente, relacionado a situações reais de uso da língua, ou seja, alfabetizar letrando.

RC: 98312

Disponível em:

https://www.nucleodoconhecimento.com.br/educacao/desenvolvimento-daconsciencia 
Diante do exposto pressupõe-se, que crianças que internalizam esse processo, desde o início de sua aprendizagem, mais facilidade terão ao aprender a ler e a escrever.

Desse modo, entende-se que, embora ainda se tenha muito a estudar sobre o tema, o que foi proposto neste artigo pode contribuir para o aprendizado das crianças, uma vez que os jogos digitais aqui sugeridos são divertidos e auxiliam no desenvolvimento da consciência fonológica, no processo inicial alfabetização.

\section{REFERÊNCIAS}

ALVES, L. R. G. Jogos eletrônicos e violência: o retorno. Revista Universitária do Audiovisual, 2009. Disponível em: http://www.rua.ufscar.br/jogos-eletronicos-eviolencia-o-retorno/. Acesso em: 05 set. 2020.

ALVES, L. R. G., MINHO, M. R. S.; DINIZ, M. V. C. (2014). Gamificação: diálogos com a educação. In: Fadel, L. M. et al. (Org.). Gamificação na Educação (pp. 7497). São Paulo, Pimenta Cultural. 2014.

BRASIL. Ministério da Educação. Secretaria de Educação Continuada, Alfabetização e Diversidade Série Mais Educação Educação Integral Caderno Cultura Digital. A Cultura Digital: quando a tecnologia se enreda aos usos e fazeres do nosso dia a dia. 2010. Disponível em: http://portal.mec.gov.br/index.php?option=com_docman\&view=download\&alias=8210 -cultura-digital-final-versao-preliminar-pdf\&category_slug=junho-2011pdf\&Itemid=30192. Acesso em: 10 set. 2020.

BRASIL. Ministério da Educação. Pacto Nacional pela Alfabetização na Idade Certa (PNAIC). Consciência Fonológica. Fevereiro/2013. Disponível em: http://www.cead.ufop.br/site_antigo/images/CONSCINCIA_FONOLGICA_REVISTO_ ABRIL_2013.pdf. Acesso em: 13 out. 2020.

RC: 98312

Disponível em:

https://www.nucleodoconhecimento.com.br/educacao/desenvolvimento-daconsciencia 
BRASIL. Ministério da Educação. Base Nacional Comum Curricular. Versão final homologada da Educação Infantil ao Ensino Fundamental em 20/12/2017. Disponível em: http://download.basenacionalcomum.mec.gov.br/. Acesso em: 13 set. 2020.

CAPOVILLA, A. G. S.; CAPOVILLA, F. C. Efeitos do treino de consciência fonológica em crianças com baixo nível socioeconômico. Psicologia Reflexão e Critica. (2000a).

CAPOVILLA, A; CAPOVILLA, F. Problemas de Leitura e Escrita: como identificar, prevenir e remediar, numa abordagem fonológica. São Paulo, SP: Memnon, 2000b.

CEALE. Centro de alfabetização, leitura e escrita. Magda Soares responde. FAE UFMG, 2015. http://www.ceale.fae.ufmg.br/pages/view/magda-soares-responde1.html\#: :text=Quando\%20se\%20fala\%20em\%20consci\%C3\%AAncia,e\%20finalme nte\%20de\%20consci\%C3\%AAncia\%20fon\%C3\%AAmica. Acesso em: 20 out. 2020.

CIEB. Centro de Inovação para a Educação Brasileira. Nota Técnica \#10. Níveis de maturidade na adoção de tecnologia pela escola. 10 fevereiro/2018. Disponível em: https://cieb.net.br/wp-content/uploads/2019/06/CIEB-Notas-T\%C3\%A9cnicas10-Niveis-de-Maturidade-na-Adocao-de-Tecnologia-2019.pdf. Acesso em: 13 out. 2020.

FERNANDES, C. W. R.; RIBEIRO, E. L. P. Games, gamificação e o cenário educacional brasileiro. CIET EnPED - Congresso Internacional de Educação e Tecnologias. Encontro de Pesquisadores em Educação a Distância. 26/06 a 13/07. 2018. Disponível em: https://cietenped.ufscar.br/submissao/index.php/2018/article/view/344. Acesso em: 13 out. 2020.

GAMES. Aplicativo: Disponível em: http:// www.4Shared.com. Acesso em: 10 out. 2020.

$\mathrm{RC}: 98312$

Disponível em:

https://www.nucleodoconhecimento.com.br/educacao/desenvolvimento-daconsciencia 
GAMES. Aplicativo: Disponível em: http://www,google.com.br. Acesso em: 10 out. 2020.

GIL, A. C. Como elaborar projetos de pesquisa. 5. ed. São Paulo: Atlas, 2010.

MACHADO, F. C.; LIMA, M. F. W. P. L. O uso da tecnologia educacional: um fazer pedagógico no cotidiano escolar. SCIENTIA CUM INDUSTRIA, V. 5, N. 2, PP. 44 50 , 2017.

Disponível

em:

http://www.ucs.br/etc/revistas/index.php/scientiacumindustria/article/view/5280.

Acesso em: 13 out. 2020.

MORAIS, A. G. Sistema de escrita alfabética. São Paulo: Melhoramentos, 2012. (Como eu ensino).

PICCOLI, L.; CAMINI, P. Práticas pedagógicas em Alfabetização: espaço, tempo e corporeidade: eixos Linguísticos da Alfabetização. São Paulo, 2012.

RICO, R. NOVA ESCOLA. O que a BNCC propõe para a alfabetização? [201-]. Disponível em: https://novaescola.org.br/bncc/conteudo/40/o-que-a-bncc-propoepara-a-alfabetizacao. Acesso em: 05 set. 2020.

ROCHA, R. Palavras, muitas palavras. Rio de Janeiro: Editora Salamandra, 2013.

ROJO, R. (org.). Escola conectada: os multiletramentos e as Tlcs. São Paulo: Parábola, 2013.

SAE DIGITAL. Tecnologia Educacional: Como ensinar as novas Gerações. Disponível em: https://sae.digital/tecnologia-educacional/. Acesso em: 20 out. 2020.

SANTA CATARINA. Secretaria de Estado da Educação. Proposta Curricular de Santa Catarina: formação integral da Educação Básica. Estado de Santa Catarina: Secretaria de Estado da Educação, 2014.

RC: 98312

Disponível em:

https://www.nucleodoconhecimento.com.br/educacao/desenvolvimento-daconsciencia 
SANTOS, J. R. O.; YAMAKAWA, I. A. A leitura e o letramento literário em perspectiva: discutindo abordagens, matizando conceitos. REVISTA X, Curitiba, volume: 12, n. 3, p. 84 - 101, 2017. Disponível em: https://revistas.ufpr.br/revistax/article/view/50172. Acesso em: 05 set. 2020.

SANTOS, E. F. G.; CRUZ, D. M.; PAZZETO, V. T. Ambiente Educacional Rico em Tecnologia: A Busca do Sentido. 22 de novembro de 2005. ABED - Associação Brasileira de Educação a Distância. Disponível em: http://www.abed.org.br/site/pt/midiateca/textos_ead/634/2005/11/ambiente_educacio nal_rico_em_tecnologia_a_busca_do_sentido. Acesso em: 04 ago. 2020.

SIGNORI, G. G.; GUIMARÃES, J. C. F.; CORRÊA, S. Gamificação como Método de Ensino Inovador. XVI Mostra de Iniciação Científica, Pós-graduação, Pesquisa e Extensão Universidade de Caxias do Sul outubro 28, 2016 - outubro 29, 2016. Disponível:

http://www.ucs.br/etc/conferencias/index.php/mostraucsppga/xvimostrappga/paper/vi ewFile/4747/1612. Acesso em: 20 out. 2020.

SILVA, C. B. O. Instrução programada: tecnologia educacional aplicada ao EAD. REVISTA DE TECNOLOGIA APLICADA (RTA) v.4, n.3, Set-Dez 2015, p.32-52. Disponível em: http://www.cc.faccamp.br/ojs-2.4.8-2/index.php/RTA/article/view/901. Acesso em: 13 out. 2020.

SOARES, M. Alfabetização: a questão dos métodos. São Paulo: Ática, 2016.

SOARES, M. Letrar é mais que alfabetizar. Jornal do Brasil, 2000.

SOARES, M. Alfaletrar-Alfabetização e letramento. Youtube. Nova Escola. 19 jul. 2017.

RC: 98312

Disponível em:

https://www.nucleodoconhecimento.com.br/educacao/desenvolvimento-daconsciencia 
VIEIRA, M. S. P. Letramento digital: o uso de tecnologias da informação e da comunicação no ensino da leitura. Anais do SILEL. Volume 3, Número 1. Uberlândia: EDUFU, 2013.

ZORZI, J. L. As letras falam- Manual de aplicação. São Paulo: Phonics.Editora, 2017.

\section{APÊNDICE - REFERÊNCIA NOTA DE RODAPÉ}

3. De acordo com Gil (2010), pesquisa básica aglutina estudos que tem como objetivo completar uma lacuna no conhecimento.

4. Trata-se de ouvir os sons das palavras e representar esses sons pelos grafemas.

5. Conhecimento sobre a estrutura sonora da língua pela criança.

6. Conforme SAE Digital. Disponível em: https://sae.digital/tecnologia-educacional/. Acesso em 20 out. 2020.

7. Conforme SAE Digital. Disponível em: https://sae.digital/tecnologia-educacional/. Acesso em: 20 out. 2020.

Enviado: Dezembro, 2020.

Aprovado: Outubro, 2021.

RC: 98312

Disponível em:

https://www.nucleodoconhecimento.com.br/educacao/desenvolvimento-daconsciencia 